\title{
Review Article \\ Review and Outcome of Prolonged Cardiopulmonary Resuscitation
}

\author{
Houssein Youness, ${ }^{1}$ Tarek Al Halabi, ${ }^{2}$ Hussein Hussein, ${ }^{1}$ Ahmed Awab, \\ Kellie Jones, ${ }^{1}$ and Jean Keddissi ${ }^{1}$ \\ ${ }^{1}$ University of Oklahoma, 920 Stanton L Young Boulevard, WP 1310, Oklahoma City, OK 73104, USA \\ ${ }^{2}$ Lebanese American University, Lebanon \\ Correspondence should be addressed to Houssein Youness; houssein-youness@ouhsc.edu
}

Received 18 August 2015; Revised 29 November 2015; Accepted 22 December 2015

Academic Editor: Giuseppe Ristagno

Copyright (C) 2016 Houssein Youness et al. This is an open access article distributed under the Creative Commons Attribution License, which permits unrestricted use, distribution, and reproduction in any medium, provided the original work is properly cited.

The maximal duration of cardiopulmonary resuscitation (CPR) is unknown. We report a case of prolonged CPR. We have then reviewed all published cases with CPR duration equal to or more than 20 minutes. The objective was to determine the survival rate, the neurological outcome, and the characteristics of the survivors. Measurements and Main Results. The CPR data for 82 patients was reviewed. The median duration of CPR was 75 minutes. Patients mean age was $43 \pm 21$ years with no significant comorbidities. The main causes of the cardiac arrests were myocardial infarction (29\%), hypothermia (21\%), and pulmonary emboli (12\%). $74 \%$ of the arrests were witnessed, with a mean latency to CPR of $2 \pm 6$ minutes and good quality chest compression provided in $96 \%$ of the cases. Adjunct therapy included extracorporeal membrane oxygenation (18\%), thrombolysis (15.8\%), and rewarming for hypothermia (19.5\%). 83\% were alive at 1 year, with full neurological recovery reported in 63 patients. Conclusion. Patients undergoing prolonged CPR can survive with good outcome. Young age, myocardial infarction, and potentially reversible causes of cardiac arrest such as hypothermia and pulmonary emboli predict a favorable result, especially when the arrest is witnessed and followed by prompt and good resuscitative efforts.

\section{Introduction}

Cardiopulmonary resuscitation (CPR) using closed-chest cardiac massage technique was first used in 1960 by Kouwenhoven in 17 patients with cardiac asystole and 3 patients with ventricular fibrillation, with a successful resuscitation in 14 patients (70\%) [1]. There are currently no firm guidelines regarding the duration of such resuscitation [2]. In one large study, the overall median duration of resuscitation for inhospital cardiac arrest was 17 minutes with an interquartile range of 10-26 min [3]. For out-of-hospital arrest, the National Association of Emergency Medical Services Physicians suggest that resuscitative efforts could be terminated in patients who do not respond to at least 20 minutes of advanced life support care [4]. The current overall survival rate to hospital discharge is $17 \%$ for in-hospital cardiac arrest and $5 \%$ for out-of-hospital cardiac arrest $[5,6]$. Despite this overall poor prognosis, multiple cases of successful prolonged resuscitation with neurologically intact survival have been reported.

In this paper we describe a case of prolonged resuscitation with successful outcome. Since there is no randomized trials that have evaluated the duration of resuscitation and the bulk of information regarding the duration of resuscitation in various conditions such as hypothermia relies on case series and expert opinion, we reviewed all reported cases of prolonged resuscitation in the English literature. Our goal was to determine the success rate and neurological outcome of these patients and to define the characteristics of patients who might benefit from such heroic measures.

\section{Case Report}

A 76-year-old African American man was admitted to the orthopedics service with a right midtibial fracture. He has a past medical history of diabetes, anemia, obstructive sleep 
apnea, hypertension, and osteoarthritis. He was taken to the operating room (OR) for open reduction and internal fixation under general anesthesia with endotracheal intubation and sciatic nerve block. Pulse oximetry, end tidal $\mathrm{CO}_{2}\left(\mathrm{ETCO}_{2}\right)$, bispectral index (BIS), and arterial line blood pressure were continuously monitored. Patient received intravenous midazolam and fentanyl and was paralyzed with cisatracurium.

During the procedure, he was in sinus rhythm with heart rate of 120 per minute, blood pressure was 136/71, and temperature was $36.2^{\circ} \mathrm{C}$, with $\mathrm{FiO}_{2}$ of 0.6 with $\mathrm{O}_{2}$ saturation of $98 \%, \mathrm{ETCO}_{2}$ of $37 \mathrm{mmHg}$, and BIS ranging from 39 to 48 during the entire procedure.

After three and half hours of general anesthesia, the tourniquet was released, and immediately the blood pressure dropped to $50 / 30 \mathrm{mmHg}$, the heart rate decreased to 20 beats per minute, $\mathrm{O}_{2}$ saturation dropped to 80 , and the ETCO $_{2}$ dropped to $7 \mathrm{mmHg}$. The patient became pulseless and CPR was immediately started. The initial rhythm was pulseless electrical activity (PEA). Epinephrine and vasopressin were given intravenously. Acute massive pulmonary embolism was suspected. Aspiration from left internal jugular central line was done for possible air embolism. Emergent transesophageal ultrasound was performed and showed a dilated right ventricle, with poor systolic function, and hyperdynamic left ventricle. Heparin bolus of 10,000 units was administered. Systemic thrombolytic therapy was contraindicated with the open leg wound. Despite resuscitation for 20 minutes, the patient remained in PEA. The catheterization lab was activated to attempt percutaneous embolectomy. CPR was continued en route with continuous $\mathrm{ETCO}_{2}$ monitoring which was maintained above $20 \mathrm{mmHg}$. Multiple providers switched every 2-3 minutes to maintain good quality chest compression, as measured by the end tidal $\mathrm{CO}_{2}$. Upon arriving in the catheterization laboratory the patient had return of spontaneous circulation (ROSC) to normal sinus rhythm. Total CPR duration was $86 \mathrm{~min}$ during which the rhythm remained PEA. No cardioversion was performed. Medications given during CPR included $5 \mathrm{mg}$ of epinephrine followed by a drip at 50 micrograms $/ \mathrm{min}, 40$ units of vasopressin, $2 \mathrm{mg}$ of atropine, $100 \mathrm{meq}(100 \mathrm{mmol})$ of bicarbonate, and $2 \mathrm{gm}(13.6 \mathrm{mmol})$ of calcium chloride for low ionized calcium level $(1.09 \mathrm{mmol} / \mathrm{L}$, normal in our lab is greater than $1.12 \mathrm{mmol} / \mathrm{L})$. Bicarbonate was given due to the concern for severe acidosis in the context of prolonged PEA ( $\mathrm{pH}$ down to 6.9 during the code). BIS was continuously monitored and remained above 80 during the entire resuscitation.

Pulmonary angiogram revealed multiple bilateral distal pulmonary emboli. No saddle or proximal pulmonary artery emboli were seen. A retrievable inferior vena cava filter was placed and patient was transferred to the intensive care unit. Following return from the cath lab, therapeutic hypothermia was instituted given persistent Glasgow coma scale of 8 . A temperature of $33^{\circ} \mathrm{C}$ was targeted. This was maintained for $24 \mathrm{~h}$, followed by a gradual rewarming $\left(0.25^{\circ} \mathrm{C} /\right.$ hour $)$. In addition, he was anticoagulated with a heparin drip after local hemostasis was achieved at the bedside by the orthopedic surgeons. After 24 hours, the patient was rewarmed. He was successfully extubated 2 days later. He returned to neurologic baseline with normal cognition over the next several days. He was transitioned to Coumadin and was discharged home.

The decision to continue CPR beyond 20 minutes was based on the observed nature of the arrest, the availability of a large number of staff to sustain good quality CPR demonstrated by $\mathrm{ETCO}_{2}$ monitoring, and the persistence of a high BIS score suggesting persistent brain activity.

\section{Review of Published Case Reports with Prolonged Resuscitation}

3.1. Materials and Methods. We performed a PubMed search of "Prolonged Resuscitation" of all published articles from 1947 to 2013. 3,826 publications were found. Subsequent filters applied included the following: "Human Species", "Case reports", "Abstract", and "English language". 491 articles met the above criteria and were obtained by online access and through interlibrary loan. All 491 articles were reviewed by 2 pulmonary and critical care physicians. Articles were included in this study if they included a detailed description of the resuscitative effort during cardiac arrest (such as immediate cause of arrest, latency to chest compression, duration of chest compression, amount of defibrillation, and number of returns of spontaneous circulation), if such effort lasted at least 20 minutes and if there was a description of the outcome including death or neurological status.

3.2. Results. We identified 71 case reports published describing prolonged resuscitation after cardiac arrest. Some of the reports had more than 1 patient, and therefore a total of 82 patients are included in our review. All cases were published between 1980 and 2013 [7-77].

The baseline characteristics of the patients are listed in Table 1 . The mean age was $43 \pm 21$ years. The main causes for the cardiac arrests were acute myocardial infarction (AMI) (29\%), followed by hypothermia (21\%) and pulmonary emboli (PE) (12\%). Other etiologies include drug overdose (6\%) and arrhythmia (7\%). There were no cases of sepsis.

The latency to CPR had an average duration of $2 \pm$ 6 minutes (Table 2). The initial cardiac arrest rhythm was ventricular tachycardia or fibrillation in 41 cases (50\%), and pulseless electrical activity or asystole in 37 cases (45\%). The median duration of chest compression was 75 minutes with a range of 20 to 330 minutes (Table 2, Figure 1). Seven patients only had 20 to 30 minutes of resuscitation. Quality of chest compression was deemed good in $96 \%$ of the patients in these reports, even though the way this was determined is not clarified.

Several types of adjunct therapies were used (Table 3). Extracorporeal membrane oxygenation (ECMO) was used in 15 cases without the presence of a pulse, for a mean duration of $2.7 \pm 3.9$ days (range 3 minutes to 11 days). Thirteen patients received thrombolysis, including 9 out of the 10 patients with $\mathrm{PE}$, as well as 3 patients with acute myocardial infarction. Rewarming was performed in 16 of the 17 hypothermic patients (94\%). In 1 case of hypothermia, cardiac arrest occurred after starting the rewarming process, and the patient was kept hypothermic thereafter. Hypothermia after return of 
TABLE 1: Baseline characteristics of the 82 patients.

\begin{tabular}{lc}
\hline Baseline characteristics & $n=82(\%)$ \\
Age (years) & \\
Mean (SD) & $43 \pm 21$ \\
Median (range) & $42(0.1-88)$ \\
Gender, M/F & $46 / 36$ \\
Location, $n$ (\%) & \\
Inpatient & $40(49)$ \\
Outpatient & $42(51)$ \\
Preexisting disorders, $n$ (\%) & \\
HTN & $7(9)$ \\
Diabetes mellitus & $7(9)$ \\
Cardiovascular disease & $13(16)$ \\
Chronic renal insufficiency & $5(6)$ \\
Malignancy & $5(6)$ \\
Cerebrovascular disease & $1(2)$ \\
Cause of the arrest, $n$ (\%) & \\
Acute myocardial infarction & $24(29)$ \\
Hypothermia & $17(21)$ \\
Pulmonary emboli & $10(12)$ \\
Arrhythmia & $6(7)$ \\
Drug overdose & $5(6)$ \\
Hyperkalemia & $4(5)$ \\
Myocarditis & $3(4)$ \\
Drowning & $2(2)$ \\
Diabetic ketoacidosis & $2(2)$ \\
Postelectroconvulsion therapy & $1(1)$ \\
Anaphylactic shock & $1(1)$ \\
Electric shock & $1(1)$ \\
Demorrhagic shock & $1(1)$ \\
Abdominal aneurysm rupture & $1(1)$ \\
Cardiomyopathy & $1(1)$ \\
Amniotic fluid embolism & $1(1)$ \\
\hline
\end{tabular}

spontaneous circulation (ROSC) was reported in 13 patients, and cardiac pacing was done in 8 patients.

Post-ROSC complications (Table 4) were mainly respiratory $(27 \%)$, secondary to pulmonary edema and bronchopneumonia. There was 1 case of hemothorax, 2 cases of pneumothorax, and 2 reported flail chest after chest compression. Renal failure occurred in 15 patients (18\%), while liver hematoma was reported in 2 cases. There was 1 case of deformed aortic valve that was recently implanted.

Interestingly, signs of life during CPR were reported in 10 cases $(12 \%)$. These signs were present without evidence of spontaneous circulation and included making respiratory efforts [15, 22, 30], sucking on the ET tube [11], hand movements [22-24, 48], opening eyes to call [22], tracking people around [22], occasional gaging and blinking [49], remaining conscious [22, 23], responding to name [39], and following simple commands [22, 39].

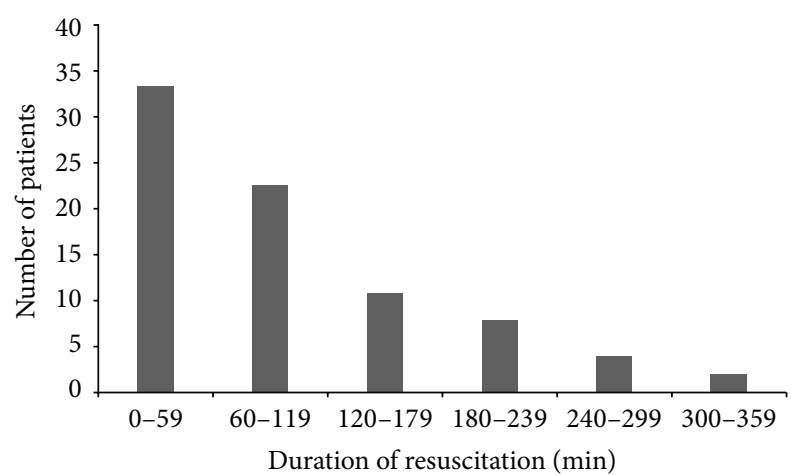

FIGURE 1: Duration of the cardiopulmonary resuscitation in the 82 patients.

3.2.1. Survival. Five patients (6\%) did not recover after resuscitation. At 28 days, 13 patients were dead (16\%). At 6 months, there was one additional death. No patient died between 6 and 12 months. The success rate of these resuscitation cases at 1 year was $68 / 82(83 \%)$.

3.2.2. Neurological Outcome. At 1 year, 50 patients (61\%) had full neurological recovery, 14 patients (17\%) had a good cerebral performance defined as a cerebral performance category (CPC) of one [78, 79], and 3 patients (4\%) had moderate neurological deficit defined as CPC of 2 . The neurological outcome was not reported in 1 patient. Overall $64 / 82(78 \%)$ of the patients had a full neurological recovery or a good cerebral performance after prolonged resuscitation.

\section{Discussion}

Studies of the effect of the duration of resuscitation on clinical outcome are few. A recent retrospective analysis of out-ofhospital cardiac arrests showed a decrease in the probability of survival to hospital discharge with a good functional outcome with each minute of cardiopulmonary resuscitation. The probability of good functional outcome after 15 minutes of CPR was down to $2 \%$, compared to $75 \%$ for patients resuscitated for 10-15 minutes [80]. In another study from Taiwan, the rate of ROSC was more than $90 \%$ in patients resuscitated for less than 10 minutes, compared to $50 \%$ when the CPR duration was more than 30 minutes [81].

Based on these studies, it appears that the need for longer resuscitation is associated with worse outcome. On the other hand, in a review by Goldberger, longer duration of resuscitation was associated with a higher survival rate, especially in patients with an initial rhythm of PEA or asystole [3]. Finally, an observational study by Cha et al. evaluated the duration of CPR and showed that resuscitation rate was $25.5 \%$ and survival rate was $5.6 \%$ when duration of CPR was more than 30 minutes [82]. The difference with our rate is most likely secondary to the publication bias inherent to the retrospective nature of our review.

Our reported and reviewed cases describe a unique group of patients that received cardiopulmonary resuscitation for a duration that far exceeded the average. In fact, the median 
TABLE 2: Characteristics of the cardiac arrests.

\begin{tabular}{lc}
\hline EKG rhythm at the beginning of CPR, $n(\%)$ & $32(39)$ \\
Ventricular fibrillation & $9(11)$ \\
Ventricular tachycardia & $21(26)$ \\
Asystole & $16(20)$ \\
Pulseless electrical activity & $1(1)$ \\
Torsade de pointes & \\
Latency to CPR (minutes) & $2.0 \pm 6$ \\
$\quad$ Mean (SD) & $0(0-40)$ \\
$\quad$ Median (range) & \\
Duration of (CPR) (minutes) & $97.5 \pm 74.8$ \\
$\quad$ Mean (SD) & $75(20-330)$ \\
$\quad$ Median (range) & \\
Quality of chest compression, $n(\%)^{*}$ & $49 / 51(96)$ \\
$\quad$ Good & $1 / 51(2)$ \\
Interrupted & $6 / 51(12)$ \\
$\quad$ Mechanical chest compression & \\
Defibrillation, $n$ & \\
$\quad$ Mean (SD) & $6.8 \pm 13.5$ \\
Median (range) & $3(0-99)$ \\
Number of return of spontaneous circulation & \\
(ROSC) & \\
Mean (SD) & $1.2 \pm 0.6$ \\
Median (range) & $1(0-3)$ \\
\hline Quality of chest compression reported in 51 patients only. & \\
&
\end{tabular}

CPR duration was 75 minutes, compared to an average of 17 minutes for in-hospital cardiac arrest [3] and 17.5 minutes for out-of-hospital cardiac arrest [80]. In addition, in $18 \%$ of the reviewed cases, the use of ECMO without a pulse was performed for a median duration of 55 minutes. This adds to the total duration of resuscitation. The 1-year survival was $83 \%$, significantly higher than the overall survival rate to hospital discharge of $17 \%$ for in-hospital cardiac arrest [5] and of $5 \%$ for out-of-hospital cardiac arrest [6]. The neurological outcome was impressive as $78 \%$ of the patients achieving a full neurological recovery or CPC1.

A major drawback in our study is the presence of publication bias. Positive results' bias occurs when authors are more likely to submit, or editors accept, positive compared to negative or inconclusive results cases [83]. Cases of prolonged resuscitation with successful outcome are more likely to be written and accepted for publication compared to similar cases with poor outcome. On the other hand, conducting a randomized controlled trial may not be ethical. Despite that we believe that our study has identified a group of patients that can benefit from prolonged resuscitation. These patients were generally young, with no significant comorbidities. The cardiac arrest etiologies were generally reversible and correctable. Most arrests were witnessed, followed by immediate CPR, with advanced life support care, including ECMO when available. These represent the chain of survival factors advocated by the 2010 American Heart Association (AHA) guidelines, which include immediate recognition and
TABLE 3: Use of adjunct therapy.

\begin{tabular}{lc}
\hline ECMO & \\
Patients in whom ECMO was used without & \\
a pulse, $n$ & \\
Duration of ECMO without pulse & $3929 \pm 5738$ \\
$\quad$ Mean in minutes (SD) & $55(3$ \\
& minutes-11 \\
$\quad$ Median (range) & days) \\
& \\
Total duration of ECMO usage (days) & $4.5 \pm 3.9$ \\
$\quad$ Mean (SD) & $3.5(1-11)$ \\
$\quad$ Median (range) & $13(15.8)$ \\
Thrombolysis, $n$ (\%) & 9 \\
Thrombolysis for pulmonary emboli & 3 \\
Thrombolysis for acute myocardial infarction & 1 \\
Thrombolysis for refractory arrhythmia & $9(11)$ \\
Stent placement, $n$ (\%) & 1 \\
Stent placement during cardiac arrest & 8 \\
Stent placement after ROSC & 16 \\
Rewarming in the 17 patients with hypothermia, $n$ & 13 \\
Hypothermia after ROSC, $n$ & $3(3.6)$ \\
Open cardiac massage, $n$ (\%) & $8(9.7)$ \\
Cardiac pacing, $n$ (\%) & $1(1.2)$ \\
Amputation of ischemic leg, $n$ (\%) & \\
\hline
\end{tabular}

ECMO: extracorporeal membrane oxygenation.

ROSC: return of spontaneous circulation.

TABLE 4: Prolonged CPR related complications after prolonged resuscitation.

\begin{tabular}{lc}
\hline Respiratory $^{*}, n$ & 22 \\
Pulmonary edema & 15 \\
Pneumonia & 7 \\
Pneumothorax & 2 \\
Hemothorax & 1 \\
Rib fracture & 4 \\
Renal failure, $n$ & 15 \\
Low ejection fraction, $n$ & 7 \\
Neurological, $n$ & \\
Intracranial hemorrhage & 3 \\
Ischemic stroke & 1 \\
Seizure & 5 \\
Bleeding disorders, $n$ & 4 \\
Rhabdomyolysis, $n$ & 4 \\
Liver hematoma, $n$ & 2 \\
Deformation of aortic valve, $n$ & 1 \\
Colon ischemia, $n$ & 1 \\
\hline
\end{tabular}

${ }^{*}$ Some patients had more than one complication.

activation, early CPR, rapid defibrillation, effective advanced life support, and integrated post-cardiac arrest care [84].

Physicians are frequently responsible for determining the maximal duration of resuscitation for each patient. We do not believe that an absolute duration of CPR is adequate for 
all patients. Rather, physicians should base the decision to continue CPR on several factors that affect the chances of survival after cardiac arrest. These factors include the patient baseline status, coexisting comorbidities, latency to $\mathrm{CPR}$, latency to defibrillation, and adequacy of chest compression which should be monitored with $\mathrm{ETCO}_{2}$ and/or diastolic blood pressure [85].

Cerebral perfusion is the goal for CPR. BIS has been used to monitor the hypnotic state in the operating room and to titrate sedation in the ICU [86]. It has also been shown to reflect changes of cerebral perfusion during resuscitation of an animal model of shock [87]. BIS monitoring during CPR was used by some to assess cerebral perfusion as well as adequacy of chest compression [88]; some authors even suggested that a level greater than 30 to 40 during CPR is a reasonable target for better neurological outcome $[89,90]$.

Even though BIS can artificially be increased by movement artifact such as chest compression [91], providers should consider the need for sedatives in patients undergoing CPR who may exhibit signs of awareness. In our case, the patient had no such signs.

While there is no proven correlation between BIS monitoring and neurological outcome after CPR, our case report shows its potential benefit; we believe that a high level should be encouraging to the team to continue their effort as it reflects adequate perfusion; however a low level is more difficult to interpret.

The underlying disease causing the cardiac arrest can significantly affect the outcome of the resuscitation. Of all etiologies, four specific diagnoses constituted $67 \%$ of all reviewed cases. These are acute myocardial infarction, hypothermia, pulmonary emboli, and drug overdose. These etiologies should deserve special consideration by the treating physician for prolongation of CPR duration as well as other adjunctive therapies such as ECMO. In fact out-of-hospital cardiac arrests of cardiac origin have been associated with a better outcome compared to those of noncardiac origin [92]. In cases of cardiac arrest secondary to hypothermia, multiple case reports indicate survival after prolonged CPR and prolonged downtime. Based on these case reports the AHA recommends continuing resuscitative effort until rewarming has been provided [93]. In 10 of our 59 reviewed patients (17\%), hypothermia was the cause of the arrest. Rewarming was provided in all these patients. Associated conditions included drowning in 1 case, diabetic ketoacidosis in 1 case, and drug overdose in 1 case. Only 1 death was reported in this population after 48 hours of admission. One study found that when cardiac arrest occurs secondary to PE, the diagnosis can be missed in $30 \%$ of the cases and thrombolytic therapy can significantly increase the rate of ROSC ( $81 \%$ versus $43 \%$, $p=0.03$ ) [94]. In our review, 7 patients (12\%) were diagnosed with $\mathrm{PE}$. All of them received thrombolytic therapy and survived to discharge with good neurological outcome. The initial rhythm was pulseless electrical activity (PEA) in 5 of the 7 patients (72\%) and asystole in the other 2, consistent with the previously reported high rate of PEA (63\%) and asystole (32\%) in patient with PE [94].

ECMO may improve outcome after cardiac arrest when compared to standard CPR [95]. It may be particularly useful in cases of witnessed arrest, brief no-flow duration or when the underlying circulatory disease is amenable to immediate cardioversion. ECMO may also be beneficial as a bridge to correcting reversible conditions such as hypothermia and drug intoxications. Fifteen patients (25.4\%) in our review were treated with ECMO. The primary cause of arrest was acute myocardial infarction (5/15), hypothermia (4/15), hyperkalemia (2/15), myocarditis (2/15), hypertrophic cardiomyopathy (1/15), and arrhythmia (1/15). There was only one reported death in this group. Fourteen patients were discharged home with good neurological function.

An interesting finding was the presence of signs of life in the absence of spontaneous pulse. These signs ranged from spontaneous respiratory effort to following commands while receiving chest compression. These signs disappeared when CPR was withheld to evaluate for ROSC. This could be explained by good CPR quality leading to a sufficient brain perfusion. In such cases, it is important to continue good resuscitative effort and minimize CPR interruption. Spontaneous pulse should only be checked at the recommended frequency to minimize brain injury from hypoperfusion.

\section{Conclusion}

Our review suggests that the decision to continue or stop CPR should not be based solely on the duration of resuscitation. Factors that affect the outcome include the patient's baseline condition, the reversibility of the cause of the arrest, the latency to starting CPR, the quality of CPR, and the availability and expertise in ECMO. It is possible to encounter signs of life during CPR which should be interpreted as evidence of good perfusion to an intact brain. It is important not to interpret these signs as evidence of ROSC and to minimize any interruption in chest compression.

\section{Authors' Contribution}

Drs. Houssein Youness and Ahmed Awab were involved in the conception and design of the study. Drs. Tarek Al Halabi and Houssein Youness were involved with data acquisition. Drs. Jean Keddissi and Houssein Youness were involved in the statistical analysis and interpretation of the data. Dr. Houssein Youness was involved in the drafting of the paper. Drs. Jean Keddissi, Ahmed Awab, Hussein Hussein, and Kellie Jones were involved in the revision of the paper.

\section{Conflict of Interests}

The authors of this paper have no conflict of interests to disclose.

\section{References}

[1] A. J. Moss, "History of electrocardiology," Annals of Noninvasive Electrocardiology, vol. 6, no. 1, pp. 78-80, 2001.

[2] L. J. Morrison, G. Kierzek, D. S. Diekema et al., "Part 3: ethics: 2010 American Heart Association guidelines for cardiopulmonary resuscitation and emergency cardiovascular care," Circulation, vol. 122, no. 18, supplement 3, pp. S665-S675, 2010. 
[3] Z. D. Goldberger, P. S. Chan, R. A. Berg et al., "Duration of resuscitation efforts and survival after in-hospital cardiac arrest: an observational study," The Lancet, vol. 380, no. 9852, pp. 14731481, 2012.

[4] E. D. Bailey, G. C. Wydro, and D. C. Cone, "Termination of resuscitation in the prehospital setting for adult patients suffering nontraumatic cardiac arrest. National Association of EMS Physicians Standards and Clinical Practice Committee," Prehospital Emergency Care, vol. 4, no. 2, pp. 190-195, 2000.

[5] M. A. Peberdy, W. Kaye, J. P. Ornato et al., "Cardiopulmonary resuscitation of adults in the hospital: a report of 14720 cardiac arrests from the National Registry of Cardiopulmonary Resuscitation," Resuscitation, vol. 58, no. 3, pp. 297-308, 2003.

[6] J. P. Ornato, M. A. McBurnie, G. Nichol et al., "The Public Access Defibrillation (PAD) trial: study design and rationale," Resuscitation, vol. 56, no. 2, pp. 135-147, 2003.

[7] T. Spangenberg, C. Frerker, R. Bader, and U. Schäfer, "Complete crush of a balloon-expandable bioprosthesis after prolonged cardiopulmonary resuscitation," Circulation: Cardiovascular Interventions, vol. 6, no. 1, pp. el-e2, 2013.

[8] A. W. Ibrahim, V. Wu, and A. M. Zafari, "Neurologically intact survival after prolonged cardiopulmonary resuscitation for pulseless ventricular tachycardia," American Journal of Medicine, vol. 126, no. 3, pp. e7-e9, 2013.

[9] T. Hifumi, N. Kiriu, H. Kato, J. Inoue, and Y. Koido, "Survival after prolonged resuscitation from cardiac arrest due to diabetic ketoacidosis using extracorporeal life support," The American journal of emergency medicine, vol. 31, no. 5, pp. 892.e1-892.e2, 2013.

[10] C.-C. Chiu, C.-W. Chiu, Y.-C. Chen, and F.-Y. Siao, "Cardiac arrest with refractory ventricular fibrillation: a successful resuscitation using extracorporeal membrane oxygenation," The American Journal of Emergency Medicine, vol. 31, no. 1, pp. 264.el-264.e2, 2013.

[11] L. Ortega, V. Bounes, N. Duchateau et al., "Prolonged cardiac arrest under circulatory support with extracorporeal membrane oxygenation," European Journal of Emergency Medicine, vol. 19, no. 2, pp. 124-126, 2012.

[12] I. Charapov and N. Eipe, "Cardiac arrest in the operating room requiring prolonged resuscitation," Canadian Journal of Anesthesia, vol. 59, no. 6, pp. 578-585, 2012.

[13] R. D. White, B. W. Goodman, and M. A. Svoboda, "Neurologic recovery following prolonged out-of-hospital cardiac arrest with resuscitation guided by continuous capnography," Mayo Clinic Proceedings, vol. 86, no. 6, pp. 544-548, 2011.

[14] K. Hosono, N. Matsumura, N. Matsuda, H. Fujiwara, Y. Sato, and I. Konishi, "Successful recovery from delayed amniotic fluid embolism with prolonged cardiac resuscitation," Journal of Obstetrics and Gynaecology Research, vol. 37, no. 8, pp. 11221125, 2011.

[15] M. Risom, H. Jørgensen, L. S. Rasmussen, and A. M. Sørensen, "Resuscitation, prolonged cardiac arrest, and an automated chest compression device," Journal of Emergency Medicine, vol. 38, no. 4, pp. 481-483, 2010.

[16] A. R. Nakstad, C. Eek, D. Aarhus, A. Larsen, and K. H. Haugaa, "Survival after prolonged resuscitation with 99 defibrillations due to Torsade De Pointes cardiac electrical storm: a case report," Scandinavian Journal of Trauma, Resuscitation and Emergency Medicine, vol. 18, article 7, 2010.

[17] F. Lapostolle, J. Levasseur, N. Dardel, and F. Adnet, "Cardiac arrest after air travel successfully treated by presumptive fibrinolysis," Resuscitation, vol. 80, no. 5, p. 606, 2009.
[18] F. Cavallaro, C. Sandroni, M. G. Bocci, and C. Marano, "Good neurological recovery after cardiopulmonary resuscitation and thrombolysis in two old patients with pulmonary embolism," Acta Anaesthesiologica Scandinavica, vol. 53, no. 3, pp. 400-402, 2009.

[19] A. Alfonzo, A. Lomas, I. Drummond, and E. McGugan, "Survival after 5-h resuscitation attempt for hypothermic cardiac arrest using CVVH for extracorporeal rewarming," Nephrology Dialysis Transplantation, vol. 24, no. 3, pp. 1054-1056, 2009.

[20] A. J. Sirianni, K. C. Osterhoudt, D. P. Calello et al., "Use of lipid emulsion in the resuscitation of a patient with prolonged cardiovascular collapse after overdose of bupropion and lamotrigine," Annals of Emergency Medicine, vol. 51, no. 4, pp. 412-415.el, 2008.

[21] S. T. Galluccio, A. Flabouris, and W. M. Griggs, "Resuscitation from prolonged cardiac arrest in a blunt trauma patient: seeking guidance through the guidelines," Injury, vol. 39, no. 7, pp. 805808, 2008.

[22] S. Bihari and V. Rajajee, "Prolonged retention of awareness during cardiopulmonary resuscitation for asystolic cardiac arrest," Neurocritical Care, vol. 9, no. 3, pp. 382-386, 2008.

[23] H.-Y. Yu, H.-L. Yeh, S.-S. Wang et al., "Ultra long cardiopulmonary resuscitation with intact cerebral performance for an asystolic patient with acute myocarditis," Resuscitation, vol. 73, no. 2, pp. 307-308, 2007.

[24] J.-S. Shin, S.-W. Lee, G.-S. Han, W.-M. Jo, S.-H. Choi, and Y.-S. Hong, "Successful extracorporeal life support in cardiac arrest with recurrent ventricular fibrillation unresponsive to standard cardiopulmonary resuscitation," Resuscitation, vol. 73, no. 2, pp. 309-313, 2007.

[25] M. Bartels, D. H. T. Tjan, E. M. Reusen, and A. R. H. van Zanten, "Therapeutic hypothermia after prolonged cardiopulmonary resuscitation for pulseless electrical activity," Netherlands Journal of Medicine, vol. 65, no. 1, pp. 38-41, 2007.

[26] R. Wise, I. Higginson, J. Benger, and N. Rawlinson, "Lower limb amputation with CPR in progress: recovery following prolonged cardiac arrest," Emergency Medicine Journal, vol. 23, article e20, 2006.

[27] W. Stockman, J. De Keyser, S. Brabant et al., "Colon ischaemia and necrosis as a complication of prolonged but successful CPR," Resuscitation, vol. 71, no. 2, pp. 260-262, 2006.

[28] A. Sheth, P. Cullinan, V. Vachharajani, and S. A. Conrad, "Bolus thrombolytic infusion during prolonged refractory cardiac arrest of undiagnosed cause," Emergency Medicine Journal, vol. 23, no. 3, article e19, 2006.

[29] H.-T. Chen, J.-R. Ong, S.-W. Hung, L.-W. Lin, and C.-F. Chong, "Survival after prolonged resuscitation from cardiac arrest in a case of severe diabetic ketoacidosis," The American Journal of Emergency Medicine, vol. 24, no. 5, pp. 633-634, 2006.

[30] S. Bercker and S. Poloczek, "A case of prolonged life support," Resuscitation, vol. 68, no. 3, pp. 434-435, 2006.

[31] R. B. Kelly, P. A. Porter, A. H. Meier, J. L. Myers, and N. J. Thomas, "Duration of cardiopulmonary resuscitation before extracorporeal rescue: how long is not long enough?" ASAIO Journal, vol. 51, no. 5, pp. 665-667, 2005.

[32] V. Fodale, C. Praticò, T. Lucanto, A. T. Mazzeo, G. Pino, and L. B. Santamaria, "Complete recovery from prolonged cardiac arrest following self-administration of cisatracurium," European Journal of Anaesthesiology, vol. 22, no. 1, pp. 73-75, 2005. 
[33] G. de Rose, N. Parenti, and A. Fanciulli, "Thrombolytic therapy during prolonged in-hospital cardiac arrest," European Journal of Emergency Medicine, vol. 12, no. 2, pp. 95-98, 2005.

[34] A. Beckhoff, A. Bürgi, and W. Ummenhofer, "Good reasons for prolonged resuscitation," Resuscitation, vol. 66, no. 3, pp. 395396, 2005.

[35] H. Sunami, Y. Fujita, T. Okada et al., "Successful resuscitation from prolonged ventricular fibrillation using a portable percutaneous cardiopulmonary support system," Anesthesiology, vol. 99, no. 5, pp. 1227-1229, 2003.

[36] T. Silfvast, M. Tiainen, E. Poutiainen, and R. O. Roine, “Therapeutic hypothermia after prolonged cardiac arrest due to noncoronary causes," Resuscitation, vol. 57, no. 1, pp. 109-112, 2003.

[37] M. Haga, K. Harasawa, Y. Morimoto, and O. Kemmotsu, "Satisfactory recovery of consciousness after prolonged cardiopulmonary resuscitation due to unexpected hemorrhage during a conduit ileum examination," Journal of Anesthesia, vol. 17, no. 3, pp. 190-192, 2003.

[38] M. W. Gibbs, K. M. Kuczkowski, and J. L. Benumof, "Complete recovery from prolonged cardio-pulmonary resuscitation following anaphylactic reaction to readministered intravenous cefazolin," Acta Anaesthesiologica Scandinavica, vol. 47, no. 2, pp. 230-232, 2003.

[39] A. Gabrielli, A. J. Layon, P. Cole, R. Holbert, J. H. Modell, and A. Idris, "Prolonged cardiopulmonary resuscitation with preservation of cerebral function in an elderly patient with asystole after electroconvulsive therapy," Journal of Clinical Anesthesia, vol. 14, no. 3, pp. 234-240, 2002.

[40] F. X. Duchateau, V. Preiss, A. Ricard-Hibon, C. Chollet, and J. Marty, "Out-of-hospital thrombolytic therapy during cardiopulmonary resuscitation in refractory cardiac arrest due to acute myocardial infarction," European Journal of Emergency Medicine, vol. 8, no. 3, pp. 241-243, 2001.

[41] S. Cooper and P. Macnaughton, "Prolonged resuscitation: a case report," Resuscitation, vol. 50, no. 3, pp. 349-351, 2001.

[42] F. Christiaens, H. Lessire, I. Dellers, B. Denis, L. Vankeerberghen, and C. Verborgh, "Successful prolonged cardiopulmonary resuscitation after a combined intoxication with a tricyclic antidepressant, a benzodiazepine and a neuroleptic," European Journal of Emergency Medicine, vol. 7, no. 3, pp. 229236, 2000.

[43] C. Winegard, "Successful treatment of severe hypothermia and prolonged cardiac arrest with closed thoracic cavity lavage," Journal of Emergency Medicine, vol. 15, no. 5, pp. 629-632, 1997.

[44] P. Mair, B. Schwarz, E. Kornberger, and D. Balogh, "Case 51997. Successful resuscitation of a patient with severe accidental hypothermia and prolonged cardiocirculatory arrest using cardiopulmonary bypass," Journal of Cardiothoracic and Vascular Anesthesia, vol. 11, no. 7, pp. 901-904, 1997.

[45] E. A. Tovar, C. Del Campo, D. W. Landa, and A. Borsari, "Successful myocardial revascularization and neurologic recovery in a patient with prolonged refractory cardiac arrest and a chronically occluded left internal carotid artery," Texas Heart Institute Journal, vol. 22, no. 3, pp. 271-273, 1995.

[46] R. Hojs, A. Sinkovič, and T. Hojs-Fabjan, "Rhabdomyolysis and acute renal failure following cardioversion and cardiopulmonary resuscitation," Renal Failure, vol. 17, no. 6, pp. 765-768, 1995.

[47] G. Quick and B. Bastani, "Prolonged asystolic hyperkalemic cardiac arrest with no neurologic sequelae," Annals of Emergency Medicine, vol. 24, no. 2, pp. 305-311, 1994.
[48] G. Lee, J. F. Antognini, and G. A. Gronert, "Complete recovery after prolonged resuscitation and cardiopulmonary bypass for hyperkalemic cardiac arrest," Anesthesia and Analgesia, vol. 79, no. 1, pp. 172-174, 1994.

[49] A. I. Jones and I. J. Swann, "Prolonged resuscitation in accidental hypothermia: use of mechanical cardio-pulmonary resuscitation and partial cardio-pulmonary bypass," European Journal of Emergency Medicine, vol. 1, no. 1, pp. 34-36, 1994.

[50] P. Husby, K. S. Andersen, A. Owen-Falkenberg, E. Steien, and J. Solheim, "Accidental hypothermia with cardiac arrest: complete recovery after prolonged resuscitation and rewarming by extracorporeal circulation," Intensive Care Medicine, vol. 16, no. 1, pp. 69-72, 1990.

[51] R. W. Langdon, W. R. Swicegood, and D. A. Schwartz, “Thrombolytic therapy of massive pulmonary embolism during prolonged cardiac arrest using recombinant tissue-type plasminogen activator," Annals of Emergency Medicine, vol. 18, no. 6, pp. 678-680, 1989.

[52] P. Y. Gueugniaud and P. Petit, "Barbiturate therapy of prolonged circulatory arrest," Critical Cre Medicine, vol. 14, no. 3, pp. 259$260,1986$.

[53] L. Osborne, A. S. Kamal El-Din, and J. E. Smith, "Survival after prolonged cardiac arrest and accidental hypothermia," British Medical Journal, vol. 289, no. 6449, pp. 881-882, 1984.

[54] P. Schissler, M. A. Parker, and S. J. Scott Jr., "Profound hypothermia: value of prolonged cardiopulmonary resuscitation," Southern Medical Journal, vol. 74, no. 4, pp. 474-477, 1981.

[55] D. A. Orr and M. G. Bramble, "Tricyclic antidepressant poisoning and prolonged external cardiac massage during asystole," British Medical Journal, vol. 283, no. 6299, pp. 1107-1108, 1981.

[56] J. Gómez-Arnau, A. Criado, M. V. Martinez, M. G. Aguilar, and F. Avello, "Hyperkalemic cardiac arrest: prolonged heart massage and simultaneous hemodialysis," Critical Care Medicine, vol. 9, no. 7, pp. 556-557, 1981.

[57] F. S. Southwick and P. H. Dalglish Jr., "Recovery after prolonged asystolic cardiac arrest in profound hypothermia. A case report and literature review," The Journal of the American Medical Association, vol. 243, no. 12, pp. 1250-1253, 1980.

[58] S. Archan, G. Prause, B. Kügler, R. Gumpert, and G. Giacomini, "Successful prolonged resuscitation involving the use of tenecteplase without neurological sequelae," American Journal of Emergency Medicine, vol. 26, no. 9, pp. 1068.e5-1068.e7, 2008.

[59] S. Braque, F. Bernard-Bertrand, N. Guillou, D. Guezennec, J. P. Canciani, and M. E. Gentili, "Successful but prolonged resuscitation after local anesthetic-induced cardiac arrest: is clonidine effective?" Acta Anaesthesiologica Belgica, vol. 59, no. 2, pp. 91-94, 2008.

[60] H. Chenaitia, M. Fournier, J. P. Brun, P. Michelet, and J. P. Auffray, "Association of mechanical chest compression and prehospital thrombolysis," The American Journal of Emergency Medicine, vol. 30, no. 6, pp. 1015.el-1015.e2, 2012.

[61] C.-W. Chiu, H.-H. Yen, C.-C. Chiu, Y.-C. Chen, and F.-Y. Siao, "Prolonged cardiac arrest: successful resuscitation with extracorporeal membrane oxygenation," American Journal of Emergency Medicine, vol. 31, no. 11, pp. 1627.e5-1627.e6, 2013.

[62] L. Craddock, B. Miller, G. Clifton, B. Krumbach, and W. Pluss, "Resuscitation from prolonged cardiac arrest with highdose intravenous magnesium sulfate," Journal of Emergency Medicine, vol. 9, no. 6, pp. 469-476, 1991.

[63] S. Dolenska, "Intraoperative cardiac arrest in acquired long QT syndrome," British Journal of Anaesthesia, vol. 102, no. 4, pp. 503-505, 2009. 
[64] A. Hughes, P. Riou, and C. Day, "Full neurological recovery from profound $\left(18.0^{\circ} \mathrm{C}\right)$ acute accidental hypothermia: successful resuscitation using active invasive rewarming techniques," Emergency Medicine Journal, vol. 24, no. 7, pp. 511-512, 2007.

[65] C. Ilsaas, P. Husby, M. E. Koller, L. Segadal, and H. Holst-Larsen, "Cardiac arrest due to massive pulmonary embolism following caesarean section. Successful resuscitation and pulmonary embolectomy," Acta Anaesthesiologica Scandinavica, vol. 42, no. 2, pp. 264-266, 1998.

[66] E. M. Koscove and N. A. Paradis, "Successful resuscitation from cardiac arrest using high-dose epinephrine therapy. Report of two cases," The Journal of the American Medical Association, vol. 259, no. 20, pp. 3031-3034, 1988.

[67] D. Martin, H. A. Werman, and C. G. Brown, "Four case studies: high-dose epinephrine in cardiac arrest," Annals of Emergency Medicine, vol. 19, no. 3, pp. 322-326, 1990.

[68] R. Oberhammer, W. Beikircher, C. Hörmann et al., "Full recovery of an avalanche victim with profound hypothermia and prolonged cardiac arrest treated by extracorporeal rewarming," Resuscitation, vol. 76, no. 3, pp. 474-480, 2008.

[69] M. Perouansky, M. Shamir, E. Hershkowitz, and Y. Donchin, "Successful resuscitation using aminophylline in refractory cardiac arrest with asystole," Resuscitation, vol. 38, no. 1, pp. 3941, 1998.

[70] T. S. Sekar, K. F. MacDonnell, P. Namsirikul, and R. S. Herman, "Survival after prolonged submersion in cold water without neurologic sequelae. Report of two cases," Archives of Internal Medicine, vol. 140, no. 6, pp. 775-779, 1980.

[71] D. J. Steedman, T. Rainer, and C. Campanella, "Cardiopulmonary resuscitation following profound immersion hypothermia," Journal of Accident and Emergency Medicine, vol. 14, no. 3, pp. 170-172, 1997.

[72] M. D. Stoneham and S. J. Squires, "Prolonged resuscitation in acute deep hypothermia," Anaesthesia, vol. 47, no. 9, pp. 784$788,1992$.

[73] G. Sumann, A. C. Krismer, V. Wenzel et al., "Cardiopulmonary resuscitation after near drowning and hypothermia: restoration of spontaneous circulation after vasopressin," Acta Anaesthesiologica Scandinavica, vol. 47, no. 3, pp. 363-365, 2003.

[74] D. J. Waters, M. Belz, D. Lawse, and D. Ulstad, "Portable cardiopulmonary bypass: resuscitation from prolonged icewater submersion and asystole," The Annals of Thoracic Surgery, vol. 57, no. 4, pp. 1018-1019, 1994.

[75] J. Wind, S. C. A. M. Bekkers, L. J. H. van Hooren, and L. W. E. van Heurn, "Extensive injury after use of a mechanical cardiopulmonary resuscitation device," American Journal of Emergency Medicine, vol. 27, no. 8, pp. 1017.e1-1017.e2, 2009.

[76] C. S. Wolfe, "Severe hypothermia associated with prolonged cardiorespiratory arrest and full recovery," The Journal of the American Board of Family Practice, vol. 6, no. 6, pp. 594-596, 1993.

[77] T. Zenda, T. Takayama, M. Miyamoto, S. Yamaguchi, T. Endo, and H. Inaba, "Intravascular gas in multiple organs detected by postmortem computed tomography: effect of prolonged cardiopulmonary resuscitation on organ damage in patients with cardiopulmonary arrest," Japanese Journal of Radiology, vol. 29, no. 2, pp. 148-151, 2011.

[78] B. Jennett and M. Bond, "Assessment of outcome after severe brain damage: a practical scale," The Lancet, vol. 305, no. 7905, pp. 480-484, 1975.

[79] R. O. Cummins, D. Chamberlain, M. F. Hazinski et al., "Recommended guidelines for reviewing, reporting, and conducting research on in-hospital resuscitation: the in-hospital 'Utstein style': a statement for healthcare professionals from the American Heart Association, the European Resuscitation Council, the Heart and Stroke Foundation of Canada, the Australian Resuscitation Council, and the Resuscitation Councils of Southern Africa," Resuscitation, vol. 34, no. 2, pp. 151-183, 1997.

[80] J. C. Reynolds, A. Frisch, J. C. Rittenberger, and C. W. Callaway, "Duration of resuscitation efforts and functional outcome after out-of-hospital cardiac arrest: when should we change to novel therapies?" Circulation, vol. 128, no. 23, pp. 2488-2494, 2013.

[81] C.-L. Shih, T.-C. Lu, J.-S. Jerng et al., "A web-based Utstein style registry system of in-hospital cardiopulmonary resuscitation in Taiwan," Resuscitation, vol. 72, no. 3, pp. 394-403, 2007.

[82] W. C. Cha, E. J. Lee, and S. Hwang, "The duration of cardiopulmonary resuscitation in emergency departments after out-of-hospital cardiac arrest is associated with the outcome: a nationwide observational study," Resuscitation, vol. 96, pp. 323327, 2015.

[83] D. L. Sackett, "Bias in analytic research," Journal of Chronic Diseases, vol. 32, no. 1-2, pp. 51-63, 1979.

[84] A. H. Travers, T. D. Rea, B. J. Bobrow et al., "Part 4: CPR overview: 2010 American Heart Association guidelines for cardiopulmonary resuscitation and emergency cardiovascular care," Circulation, vol. 122, no. 18, supplement 3, pp. S676-S684, 2010.

[85] R. W. Neumar, C. W. Otto, M. S. Link et al., "Part 8: adult advanced cardiovascular life support: 2010 American Heart Association Guidelines for Cardiopulmonary Resuscitation and Emergency Cardiovascular Care," Circulation, vol. 122, no. 18, supplement 3, pp. S729-S767, 2010.

[86] P. S. Glass, M. Bloom, L. Kearse, C. Rosow, P. Sebel, and P. Manberg, "Bispectral analysis measures sedation and memory effects of propofol, midazolam, isoflurane, and alfentanil in healthy volunteers," Anesthesiology, vol. 86, no. 4, pp. 836-847, 1997.

[87] E. Cavus, P. Meybohm, V. Doerges et al., "Effects of cerebral hypoperfusion on bispectral index: a randomised, controlled animal experiment during haemorrhagic shock," Resuscitation, vol. 81, no. 9, pp. 1183-1189, 2010.

[88] B. Szekely, T. Saint-Marc, A.-C. Degrémont, M.-H. Castelain, and M. Fischler, "Value of bispectral index monitoring during cardiopulmonary resuscitation," British Journal of Anaesthesia, vol. 88, no. 3, pp. 443-444, 2002.

[89] N. Fàbregas, P. L. Gambús, R. Valero et al., "Can bispectral index monitoring predict recovery of consciousness in patients with severe brain injury?" Anesthesiology, vol. 101, no. 1, pp. 43-51, 2004.

[90] M. Chakravarthy, T. Patil, K. Jayaprakash, N. Shivananda, and V. Jawali, "Bispectral index is an indicator of adequate cerebral perfusion during cardiopulmonary resuscitation," Journal of Cardiothoracic and Vascular Anesthesia, vol. 17, no. 4, pp. 506508, 2003.

[91] D. M. Fatovich, I. G. Jacobs, A. Celenza, and M. J. Paech, "An observational study of bispectral index monitoring for out of hospital cardiac arrest," Resuscitation, vol. 69, no. 2, pp. 207-212, 2006.

[92] M. Kuisma and A. Alaspää, "Out-of-hospital cardiac arrests of non-cardiac origin: epidemiology and outcome," European Heart Journal, vol. 18, no. 7, pp. 1122-1128, 1997.

[93] T. L. Vanden Hoek, L. J. Morrison, M. Shuster et al., "Part 12: cardiac arrest in special situations: 2010 American Heart 
Association Guidelines for Cardiopulmonary Resuscitation and Emergency Cardiovascular Care," Circulation, vol. 122, no. 18, supplement 3, pp. S829-S861, 2010.

[94] I. Kürkciyan, G. Meron, F. Sterz et al., "Pulmonary embolism as cause of cardiac arrest: presentation and outcome," Archives of Internal Medicine, vol. 160, no. 10, pp. 1529-1535, 2000.

[95] International Liaison Committee on Resuscitation, "Part 6: paediatric basic and advanced life support," Resuscitation, vol. 67, no. 2-3, pp. 271-291, 2005. 


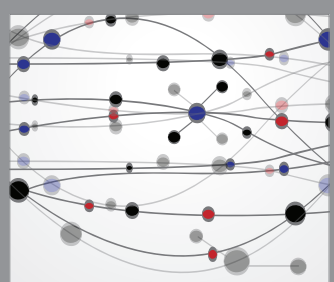

The Scientific World Journal
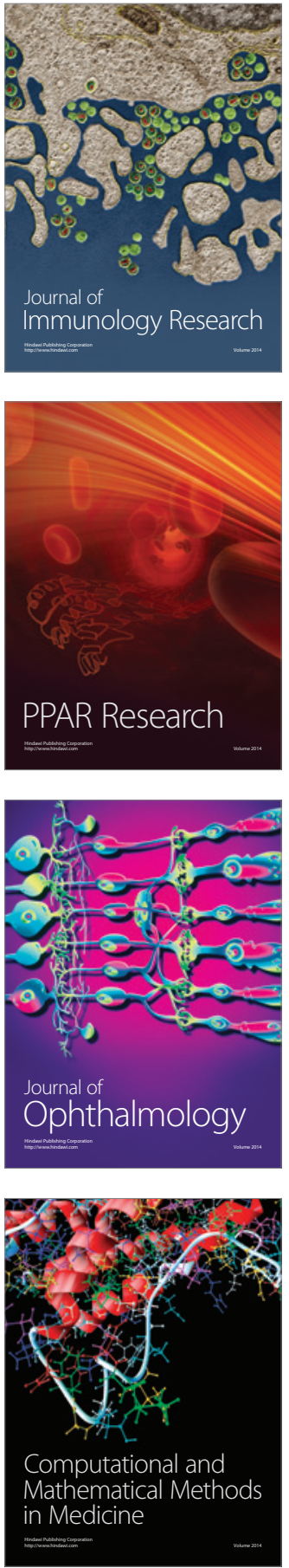

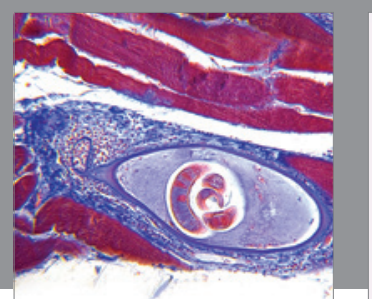

Gastroenterology Research and Practice

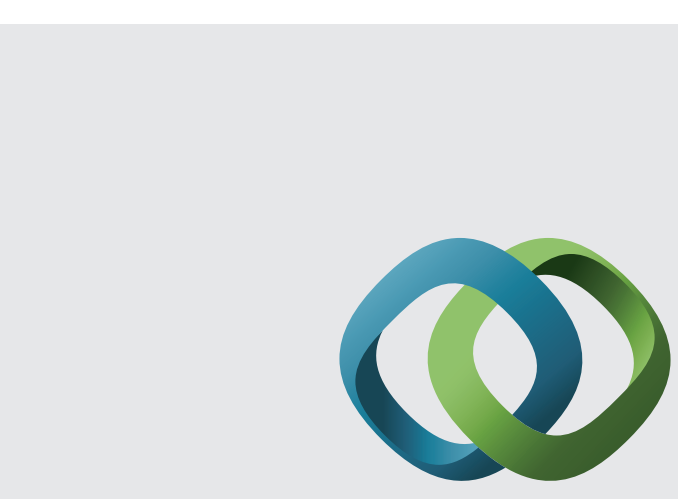

\section{Hindawi}

Submit your manuscripts at

http://www.hindawi.com
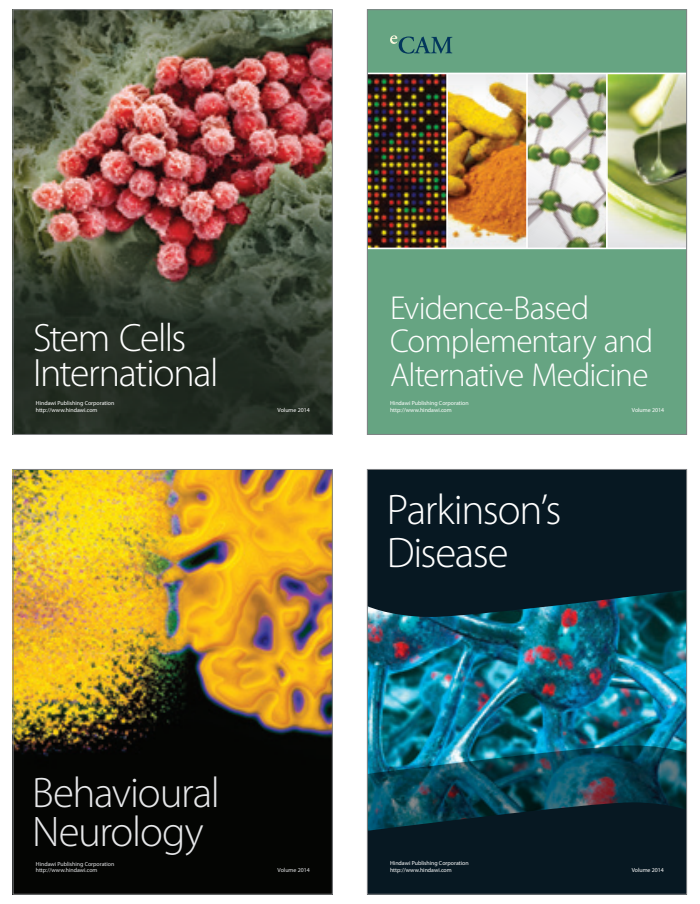
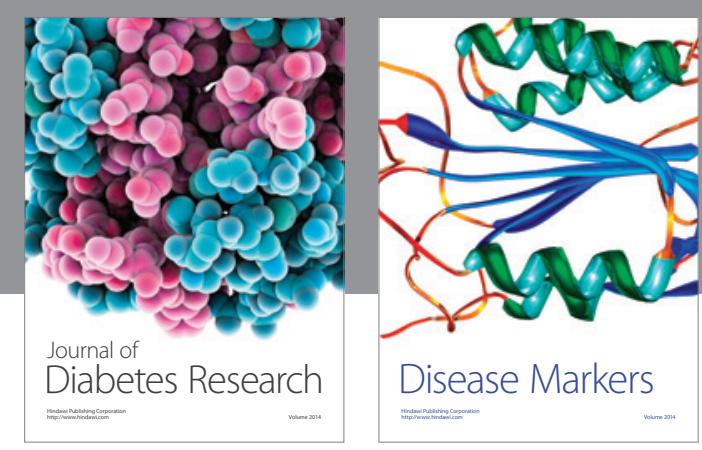

Disease Markers
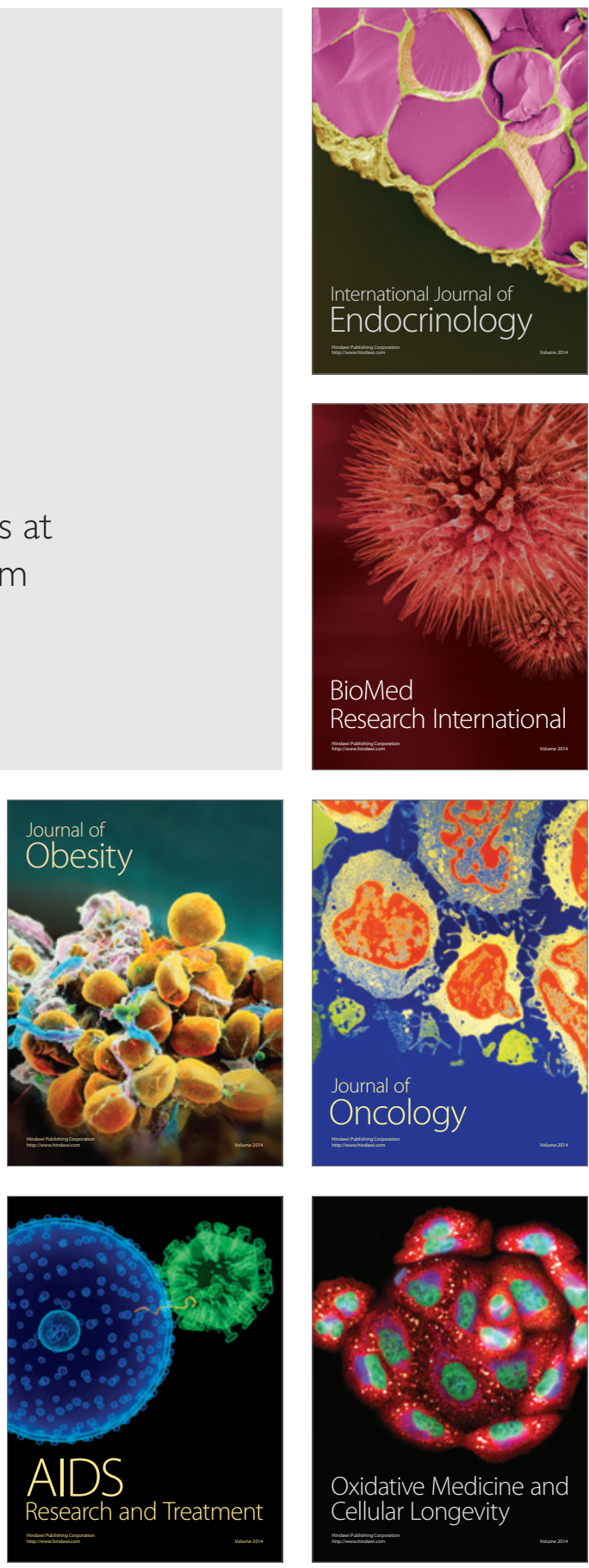